\title{
Miniscrew-supported coil spring for molar uprighting: Description
}

\author{
Antônio Carlos de Oliveira Ruellas¹, Matheus Melo Pithon², Rogério Lacerda dos Santos 3
}

Introduction: Since the beginning of miniscrews as orthodontic anchorage, many applications have been described in the literature. Among these, one is the uprighting of mesially inclined molars. In regard to the mechanical aspects, however, there is little information about the application of orthodontic forces using such devices. Objective: The objective of this study was to describe a miniscrew supported spring for uprighting of mesially inclined molars. With this device, one can achieve the correct use of orthodontic biomechanics, thus favoring more predictable tooth movements and preventing unwanted movements from occurring. Keywords: Molar tooth. Corrective orthodontics. Dental implant.

Introdução: desde o surgimento dos mini-implantes como recurso de ancoragem ortodôntica, muitas aplicações têm sido descritas na literatura. Entre essas, cita-se a verticalização de molares inclinados para mesial. No entanto, pouco se fala da correta aplicação das forças ortodônticas nesses dispositivos, sob o ponto de vista mecânico. Objetivos: o objetivo desse artigo foi demonstrar uma mola mini-implante suportada para verticalizar molares inclinados para mesial. Com esse dispositivo consegue-se correta aplicação da mecânica ortodôntica, favorecendo movimentos mais previsíveis e minimizando os movimentos indesejáveis.

Palavras-chave: Dente molar. Ortodontia corretiva. Implante dentário.

\section{INTRODUCTION}

The early loss of primary molars or permanent first molars is a routine problem in the orthodontic clinic and results in mesial inclination of the first, or second and third molars, depending on the extracted or missing tooth. ${ }^{1,2}$

Mesial inclination favors the appearance of vertical bone defects and infra-osseous pockets in the mesial region of molars, distal migration of premolars, extrusion of the antagonist molar, premature contacts in centric relation, occlusal interferences during lateral and protrusive movements, in addition to, it is difficulty in pros-

${ }^{1}$ Associate Professor of Orthodontics, UFRJ

${ }^{2}$ Professor of Orthodontics, Southwest Bahia State University - UESB.

${ }^{3}$ Professor, Federal University of Campina Grande.

How to cite this article: Ruellas ACO, Pithon MM, Santos RL. Miniscrewsupported coil spring for molar uprighting: description. Dental Press J Orthod. 2013 Jan-Feb; 18(1):45-9. thetic adaptation when the inclination is excessive. ${ }^{3,4}$

Molar uprighting into its correct position leads to the normalization of functional and periodontal occlusion situation, enabling the roots to be positioned perpendicular to the occlusal plane so that they are better able to resist to occlusal forces, in addition to facilitating the plane of insertion of the prosthesis parallel to the long axis of the tooth. ${ }^{5}$

With the advent of the use of miniscrews as orthodontic anchorage, molar uprighting procedures have

\begin{abstract}
Submitted: April 17, 2009 - Revised and accepted: June 8, 2009
" The author reports no commercial, proprietary or financial interest in the products or companies described in this article.

" Patients displayed in this article previously approved the use of their facial and intraoral photographs.
\end{abstract}

Contact address: Antônio Carlos de Oliveira Ruellas

Rua Rodolpho Paulo Rocco, 325, Cidade Universitária, Rio de Janeiro/RJ - Brazil CEP: 21.941-617 - E-mail: antonioruellas@yahoo.com.br 
become simpler, with more predictable results, and since there is no need to use other teeth as anchorage, there is better control of undesirable effects. ${ }^{2,4,6,7}$

The aim of this study is to describe a method for molar uprighting with the use of a spring supported on miniscrews.

\section{SPRING DESIGN}

The uprighting spring can be fabricated from stainless steel or molybdenum-titanium alloy wire with a rectangular cross section $(0.018 \times 0.025$-in). The wire is bent from the posterior in the anterior direction, allowing a segment of around $4 \mathrm{~mm}$ to pass beyond the end of the molar tube. This segment will afterwards serve to fabricate a hook (another option would be to use a double tube, and insert a wire segment into the cervical tube from the distal to the mesial region, with a hook on its lower end). Mesial to the tube, a wire is bent downwards for fabricating the helical loop. After fabricating the loop, the wire is redirected towards the anterior direction surrounding the mini-implant (MI) that will serve as its support.

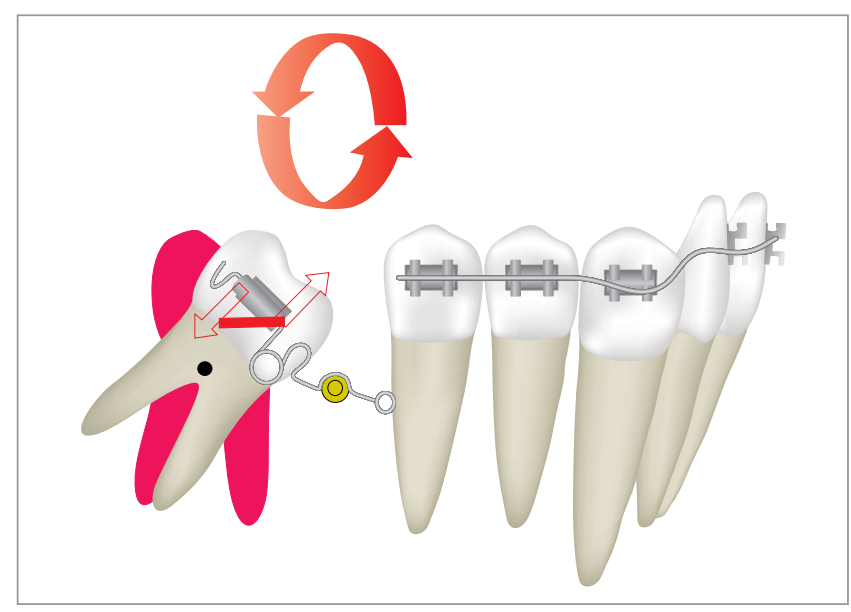

Figure 1 - Diagram demonstrating activation of the spring to obtain uprighting by distal movement of the crown and mesial movement of the root.

\section{ACTIVATION}

The spring is activated by means of tip back bends in the segment that is inserted into the molar tube, and by opening and closing the loops according to the desired function. To potentiate the tipping moment of the root in the mesial direction, when necessary, an elastic chain is inserted between the distal hook on the distal region of the tube and mini-implant. By varying the size of the hook, greater or less moment and extrusion can be obtained. The longer towards the cervical direction, the greater will be the mesial moment of the root and the greater will be the extrusion.

\section{INTENDED MOVEMENTS}

\section{Uprighting by distal inclination of the crown (Uprighting with the center of rotation at the center of resistance)}

When one wishes to perform molar uprighting with movement towards the distal direction of the crowns, and towards the mesial direction of the roots, the spring should be position with tip back activation on the segment that fits into the molar tube, without opening or closing activation of the loop. The intention is to cause the tooth to rotate around its center of resistance (Fig 1, 2).

\section{Uprighting with mesial movement of the root (Uprighting with the center of rotation in the crown)}

When one wishes to correct molar inclination with predominantly mesial movement of the root (Figs 4, 5, 6), in addition to the tip back activation performed on the wire segment inserted into the molar tube, one should insert an elastic chain from the hook in the distal region of the tube to the mini-implant, and the loop should be slightly closed $(0.5 \mathrm{~mm})$, in order to potentiate the effect. A tip back bend will create a moment of distal rotation of the crown and mesial rotation of the root. The effect of moving the root towards the mesial direction will be
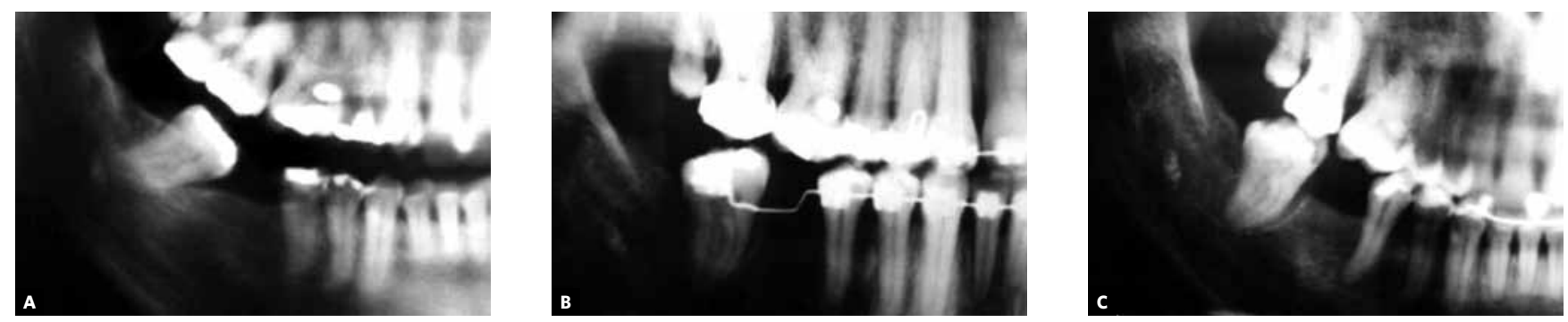

Figure 2 - Radiographic images showing clinical case with molar uprighting with distal movement of the crown and mesial movement of the root. 
potentiated by placement of the elastic chain on the distal hook of the spring (Fig 3) and activation of the spring will prevent the crown from moving in the distal direction.

\section{Uprighting with opening of spaces \\ (Uprighting with the center of rotation close to the root apex)}

When the treatment plan is to fabricate a prosthetic element (osseointegrated implant, fixed or removable denture) space must be opened (Fig 8). To achieve this movement the vertical loop of the spring must be opened, so that it is compressed between the molar tube and the mini-implant, causing the action of the force in the horizontal direction to open space (Fig 7). Tip back activation of the segment that is inserted into the molar tube must also be performed.

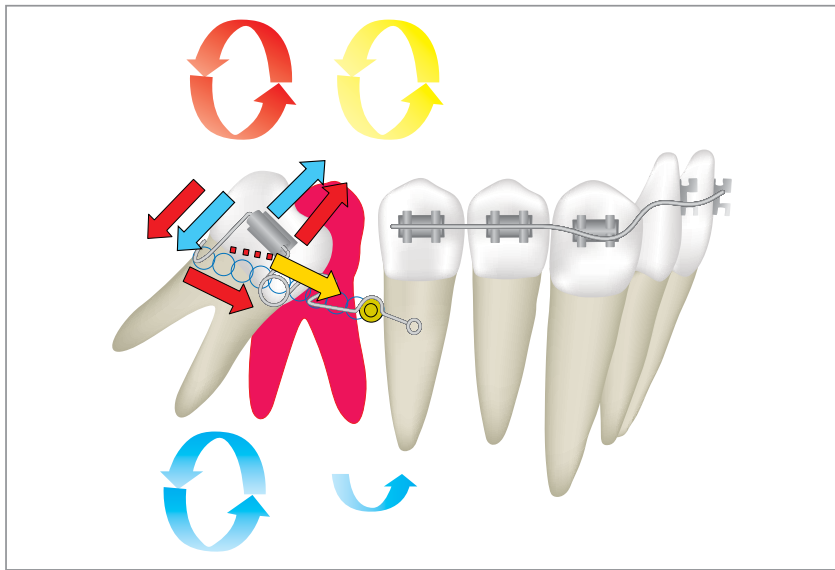

Figure 3 - Diagram demonstrating activation of the spring to obtain uprighting with mesial movement of the root.
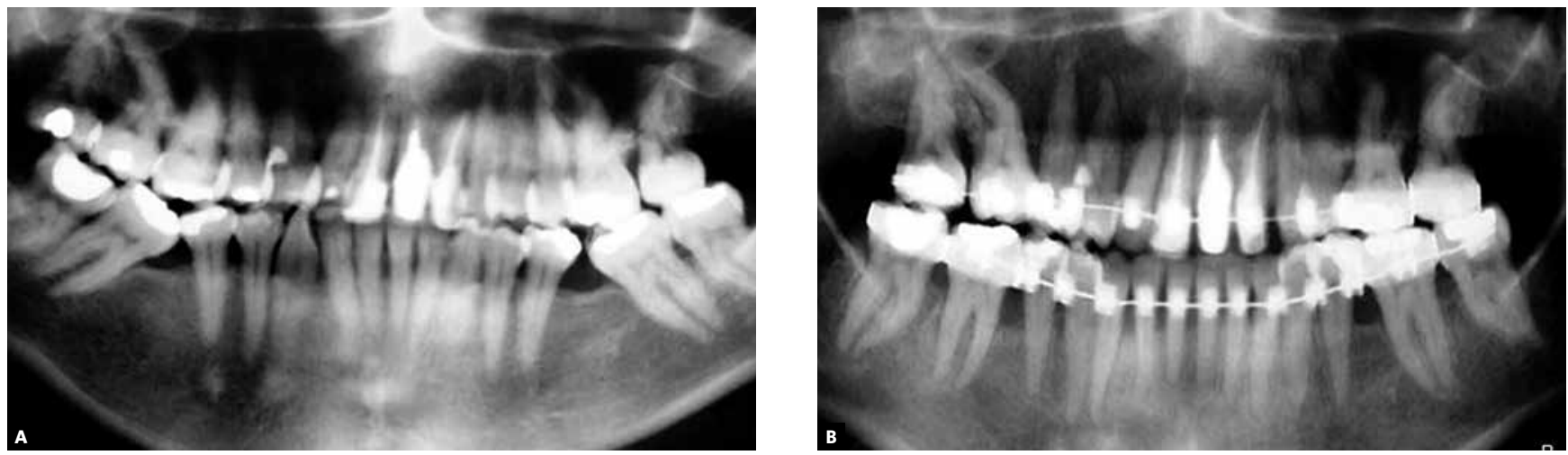

Figure 4 - Radiographic images of clinical case in which uprighting was performed with mesial movement of the root with the use of miniscrew-supported spring. A) Initial; B) Final.
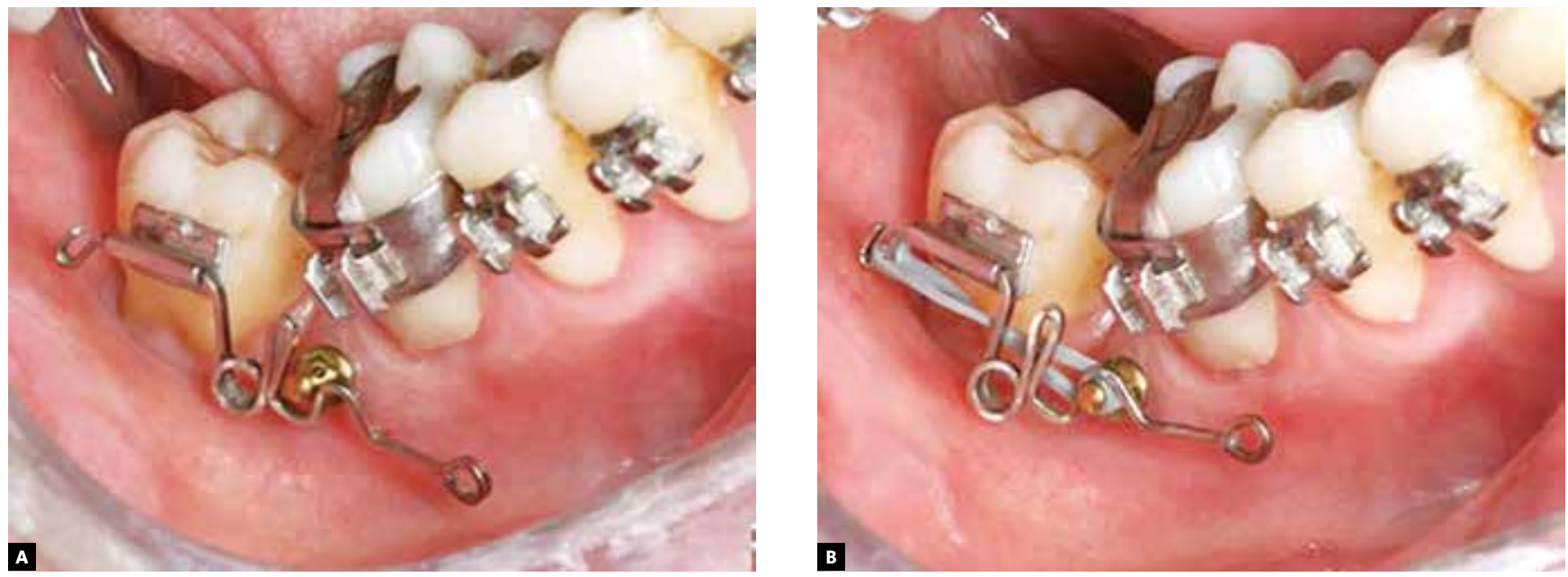

Figure 5 - Clinical case in which uprighting was performed with mesial movement of the root with the use of miniscrew-supported spring: A) pre-activated spring, B) activated spring. 

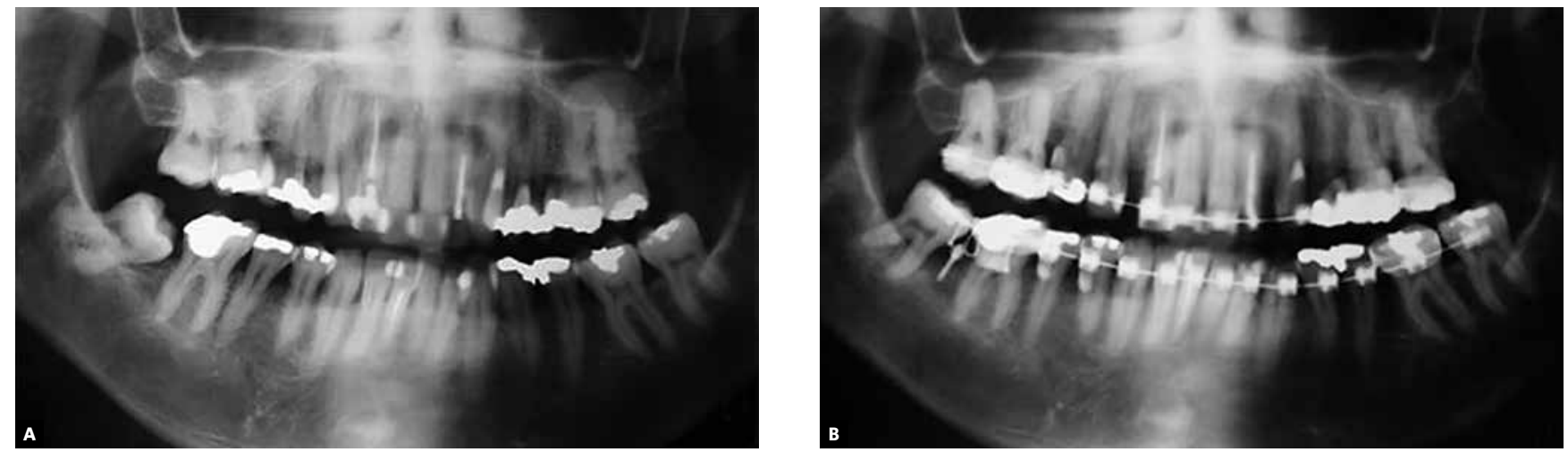

Figure 6 - Radiographic images showing the clinical case with molar uprighting with mesial movement of the root.

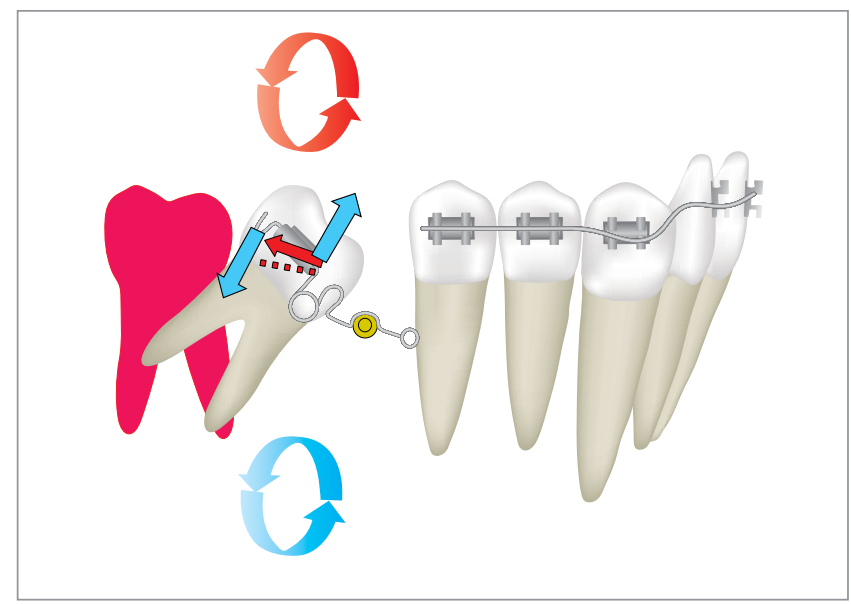

Figure 7 - Diagram demonstrating the activation of the spring to obtain molar uprighting with space opening.
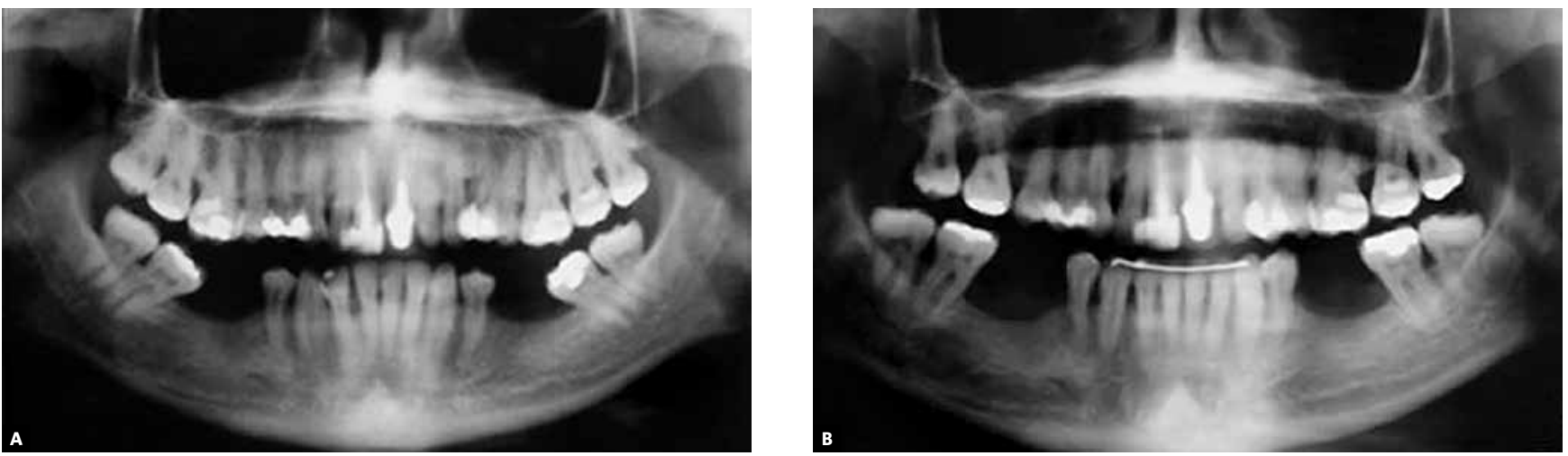

Figure 8 - Clinical case in which molar uprighting was performed with the opening of spaces with the use of miniscrew-supported spring: A Initial; B Final.

\section{DISCUSSION}

With the advent of absolute anchorage promoted by mini-implants, many situations that were previously difficult to solve in Orthodontics, have become a real possibility., ${ }^{7,9}$ Special mention is for molar uprighting, $2,3,4,6,7,10,11$ a procedure that promotes the return of the molar to its correct M-D inclination. In the litera- ture, there are infinite numbers of devices used for this purpose, however, with some deficiency in control from the mechanical point of view. $2,3,4,6,7,10,11$

The aim of the present article was to demonstrate both mechanically and clinically, the use of a special type of miniscrew-supported spring for molar uprighting. With this device, from the mechanical 
point of view, it is possible to obtain better control, and thereby makes it possible to obtain predictable results at the end of treatment.

The spring must be fabricated of a rectangular cross section wire for better three-dimensional control. Stainless steel or titanium-molybdenum alloy wire may be used. The choice of the alloy depends on the flexibility demanded by the case, the titanium-molybdenum alloy is the wire of choice for periodontally compromised teeth, as it releases more gentle forces in cases of teeth with severe mesial inclination, and when only a small quantity of wire is used for fabricating the spring (because there is little space between the MI and the tube).

Fabrication of the helical loop provides greater flexibility, in addition to performing a fundamental function when opening movements are necessary, or performing a fundamental function when movements of opening or closure of spaces is required. When the option to open space is chosen, the loop is distended, so that it is compressed between the mini-implant and tooth, and since the mini-implant does not move, the tendency is towards uprighting associated with distalization of the molar. However, when the treatment plan favors space closure, the opposite procedure must be performed; that is, close the loop distending it in the mesial direction, and activate it by means of fitting it into the mini-implant. The presence of the loop provides more effective space closure or opening, since it involves frictionless mechanics.

In all situations of uprighting, tip back activation of the segment that inserts into the molar tube is performed, causing a distal moment to act on the crown and a mesial moment on the root. Space opening or closure will be activated by additional resources.

To potentiate mesial movement of the molar root, a vertical hook is fabricated on the distal segment beyond the molar tube (or a segment of the arch with a vertical hook, inserted from the distal to the mesial region into the cervical tube of a double tube). The function of this hook is to minimize the extrusive effect, increase the effect of molar uprighting, and traction of the molar in the mesial direction. At all times, one must remember that this will depend on the vertical length of this distal rod and the result of the forces applied.

The height of the hook onto which the elastic chain is placed is the factor responsible for molar extrusion control; the longer the hook, the greater the moment of mesial rotation of the root. However, if the hook is placed cervically to the MI, there will be extrusion of the molar.

The choice of the site for the mini-implant insertion is due to the need for an alternative site, in cases in which it is not possible to place them in the retromolar region. This may occur due to the presence of third molars, absence of inserted gingiva, with predominance of alveolar mucosa and lack of space.

\section{CONCLUSIONS}

The use of a loop spring supported by miniscrews as anchorage is a simple and effective method for molar uprighting. A range of activations may be achieved, providing various movements with predictability, particularly in cases in which miniscrew insertion in the retromolar region is contraindicated.
1. Haralabakis NB, Tsianou A, Nicolopoulos C. Surgical correction of mesially impacted mandibular second molars. J Clin Orthod. 2003:37(4):209-12; quiz 204.

2. Lee KJ, Park YC, Hwang WS, Seong EH. Uprighting mandibular second molars with direct miniscrew anchorage. J Clin Orthod. 2007:41(10):627-35.

3. Sawicka M, Racka-Pilszak B, Rosnowska-Mazurkiewicz A. Uprighting partially impacted permanent second molars. Angle Orthod. 2007;77(1):148-54.

4. Sohn BW, Choi JH, Jung SN, Lim KS. Uprighting mesially impacted second molars with miniscrew anchorage. J Clin Orthod. 2007:41(2):94-7.

5. Weiland FJ, Bantleon HP, Droschl H. Molar uprighting with crossed tipback springs. J Clin Orthod. 1992:26(6):335-7.

6. Gracco A, Lombardo L, Cozzani M, Siciliani G. Uprighting mesially inclined mandibular second molars with a modified Uprighter Jet. J Clin Orthod 2007:41:281-4.
7. Carano A, Testa M, Siciliani G. The Distal Jet for uprighting lower molars J Clin Orthod. 1996:30(12):707-10

8. Upadhyay M, Yadav S. Mini-implant for intrusion: is it always justified? Am J Orthod Dentofacial Orthop. 2007:131(3):298.

9. Moon CH, Lee DG, Lee HS, Im JS, Baek SH. Factors associated with the success rate of orthodontic miniscrews placed in the upper and lower posterior buccal region. Angle Orthod. 2008;78(1):101-6.

10. Majourau A, Norton LA. Uprighting impacted second molars with segmented springs. Am J Orthod Dentofacial Orthop. 1995;107(3):235-8

11. Miao YQ, Zhong H. An uprighting appliance for impacted mandibular second and third molars. J Clin Orthod. 2006;40(2):110-6. 